\title{
The Cost Incidence of the U.K.'s NHS System
}

\author{
Paul J.M. Klumpes and Liyan Tang \\ Tanaka Business School, Imperial College London, South Kensington SW72AZ, U.K. \\ E-mails: P.Klumpes@imperial.ac.uk; 1.tang@imperial.ac.uk
}

We examine the cost incidence of the United Kingdom's National Health Service (NHS) through application of the concepts of fiscal imbalance (FI) and generational imbalance (GI). We find significant disparities of costs by gender, region and type of NHS expenditure. The financial sustainability of publicly funded health care systems is sensitive to the demographics of ageing population. Historical and current trends in the demographic structure of U.K.'s population also impact these structural imbalances underlying the system. The pay-as-you-go (PAYG) financed funding status of NHS based on both currently required cash-based accounting principles and proposed accrual-based accounting principles is criticised for not recognising the continuing service obligations of the U.K. Government under the NHS. A combination of FI and GI largely explains the under-funding of the NHS. Data are taken from both historical trends in expenditure and ageing as well as projected demographics. The analysis implies that there is a significant inter-generational inequity in the funding of the NHS.

The Geneva Papers (2008) 33, 744-767. doi:10.1057/gpp.2008.29

Keywords: cost incidence; fiscal imbalance; generational imbalance

\section{Introduction}

Public health care plans cover the substantial majority of the populations of most Organization for Economic Cooperation and Development (OECD) countries and command a substantial proportion of their governments' capital investment. ${ }^{1}$ However, unlike privately funded health care insurance, but similar to other types of publicly managed pension funds and social insurance, these plans are likely to encounter major long-term financial problems. This is because public health care systems, and most other government-provided social insurance systems rely on a "pay-as-you-go" funding arrangements (PAYG), whereby promised benefits and services are usually paid for by the current active workforce in the form of government taxes. However, the political will of governments to continue funding these promises via PAYG are coming under threat because the populations of most advanced capitalist economies are ageing. This raises concern whether a government's existing and potential revenues will be sufficient to financially sustain current levels of public health care into the future. ${ }^{2}$

Appleby $^{3}$ suggests that a major issue in the accountable financial management of any public health care system is to provide information about: (a) who pays, (b) how

\footnotetext{
${ }^{1}$ OECD (2006).

2 Ibid.

${ }^{3}$ Appleby (1992).
} 
these payments are allocated, and (c) how they are used in return for a standard level of community treatment and care. However, prior researchers evaluating the accounting control and financial management of health care systems have until now paid scant attention to the accountability implications of under-funded public health care services. ${ }^{4}$ The purpose of this paper is to explore the nature and extent of the U.K.'s under-funded public health care sector system so as to better understand the inter-generational equity considerations affecting the financial management of these important institutions. ${ }^{5}$

In general, taxpayers, employees and government agencies should be concerned about the build-up of assets and liabilities affecting PAYG-funded health care systems for several reasons. As populations age, all else being equal, the growth rate of liabilities will eventually outstrip the growth rate of assets. Consequently, over time these systems can represent a major form of public borrowing against the future, which has important accounting implications. ${ }^{6}$ They may also powerfully affect future revenue-raising potentials of governments and the health care premiums established by private health care firms. Finally, PAYG-funded public health care systems involve both distributional inequity through the provision of benefits to dependants without additional contributions and inter-generational inequity. ${ }^{7}$ Such inequities are not recognised by either cash- or accrual-based accounting principles that are now being used in many public sector contexts. ${ }^{8}$

For this reason, generational accounting has been proposed as a method that considers the implied burden on future generations, by dealing with how the levels of these contributions and benefits will grow over time including growth arising from demographic change. ${ }^{9}$ Generational accounting explicitly recognises generational imbalance (GI) between three inter-related variables affecting PAYG funding: (1) required health care contributions, (2) actual annual health care contributions and (3) health care expenditures and benefit payments. This study applies the concept of generational accounting to improve understanding of the full intergenerational equity implications of continuing reliance on the under-funding of the National Health Service (NHS), the U.K.'s PAYG-financed universal public health care system.

The U.K. institutional setting is interesting for three reasons. First, like many other OECD countries, the U.K. population is ageing and this has important implications for understanding the inter-generational equity effects upon savings, investment, and

${ }^{4}$ Chua and Preston (1994); Lapsley (1998); Lawrence et al. (1994).

${ }^{5}$ In 1998, the U.K. Government committed itself to the preparation of Whole of Government Accounts (H.M. Treasury, 1998).

${ }^{6}$ Loeb (1987).

${ }^{7}$ Danzon (1993).

${ }^{8}$ The Public Sector Committee of the International Federation of Accountants recently issued a number of exposure drafts for international standards in whole-of-government accounting. Their proposed accounting standards assume that government accounts are prepared under various combinations of either cash- or accrual-based accounting. However, these standards ignore present value calculations and assume that under-funded commitments for social insurance programmes are not liabilities of governments.

9 Auerbach et al. (1991). 
insurance behaviour. ${ }^{10}$ Second, under U.K. Law, participation in the NHS became compulsory in 1948 with the National Health Service Act of 1946. This universal system offers free treatment to all U.K. residents in a public hospital and free or subsidised treatment by practitioners. However, the NHS budget is constrained by government (similar to Canada) or where participation is not universal (the United States). Third, the NHS is unique because it is under-funded public health care funded from general taxation.

The empirical analysis exploits the fiscal imbalance (FI) and GI measures developed by Gokhale and Smetters. ${ }^{11}$ These measures differ from those used by generational accounting. ${ }^{12}$ Generational accounting involves a hypothetical policy reform that restores FI to zero by increasing the net tax burden on unborn generations. Under generational accounting, the aggregate net tax burden on future generations (the implicit debt) equals the difference between expected tax burden on current generations (including current newborns not affected by hypothetical policy reform) and projected expenditures of a programme (or the budget as a whole). The per capita burden on future generations is obtained by distributing this total burden among them in a growth-adjusted manner. Because it is derived as a residual after subtracting the net tax burden on current generations, the net tax burden on future generations is a hypothetical construct and not necessarily implementable. For example, continuing current policies implies a different burden on future generations than the implicit burden calculated as above. Hence, generational accounting's measure includes a hypothetical and sustainable policy. ${ }^{13}$ In contrast, the FI and GI measures correspond to current law making them more applicable as a budget and reporting concept. One reason why the FI and GI measures are easy to understand is that they do not incorporate any hypothetical policy change. ${ }^{14}$ However, the combination of FI and GI measures are also superior to both FI and standard debt measures, which fail to take account of resources transfers across generations that some policy changes can cause.

This research builds upon prior research on the Australian Medicare system ${ }^{15}$ to analyse generational accountability of the U.K. NHS. The major difference between the Australian and the U.K. health care system is that the former is partly funded by direct taxation via a levy on contributors, whereas the latter is totally unfunded and therefore universal in nature. Consequently, the magnitude and extent of the generational accounts are much more severe for the U.K. population even though they have a similar demographic, gender and fertility profile to Australia.

The remaining sections are organised as follows. The following section discusses the sources and projections of likely ageing of the U.K. population and presents descriptive evidence of the impact of this demographic transition on the changing demand for NHS services. The next section analyses the under-funding of the NHS based on standard cash- and accrual-based accounting principles. The subsequent section outlines an alternative theoretical model of public health care under-funding

\footnotetext{
${ }^{10}$ Ablett (1996).

${ }^{11}$ Gokhale and Smetters (2003).

12 Auerbach et al. (1991).

${ }^{13}$ See OECD (2006); Hagist and Kotlikoff (2005).

${ }^{14}$ Gokhale and Smetters (2003).

15 Klumpes (2001).
} 
based on a system of generational accounting. An empirical model and results are described in the penultimate section and a discussion of its policy implications is contained in the final section.

\section{Financial and generational sustainability}

This section overviews the basic concepts related to financial and generational sensitivity of unfunded health care obligations. We first define the key concepts of financial and generational sustainability. We then briefly discuss the relative merits of this approach.

\section{Features of FI and GI}

Gokhale and Smetters ${ }^{16}$ introduce the concept of "fiscal imbalance", which adds to a government entity's current accounting-based liabilities the present value of the difference between all projected non-interest spending and all projected revenue. Following their approach, the U.K. Government's NHS programme may be considered to be financially sustainable if today's publicly held debt plus the present value of projected non-interest spending is equal to the present value of projected non-interest spending and to the present value of projected government receipts. The spending and revenue projections are made under current policies. "Present values" means that amounts paid or received in relation to the NHS programme throughout the future are discounted at the long-term gilt yield in order to reflect their true value today. A financially sustainable policy can be sustained without changing either outlays or revenues. Hence, a financially sustainable measure as of the end of year $t$ is defined as ${ }^{17}$

$$
F I_{t}=P V E_{t}-P V R_{t}-A_{t} .
$$

This definition is the excess of total expenditures over available resources in present value. $P V E_{t}$ is the present value of projected expenditures under current policies at the end of period $t, P V R_{t}$ is the present value of projected receipts under current policies, and $A_{t}$ is assets in hand at the end of period $t$.

For NHS policy to be financially sustainable, its FI must be zero. The government cannot spend and owe more than it will receive as revenue in present value. If the FI measured under current policies is positive, those policies are unsustainable and policymakers will have to change them at some future point in time.

However, the FI measure is not capable of providing the financial impact of all possible policy changes. This is because any new policy that changes projected expenditures and revenues, so that their increments are exactly equal in present value, will provide offsetting increases in $P V E_{t}$ and/or $P V R_{t}$, leaving FI unchanged. However, such FI-neutral policies could transfer net tax burden from living to future generations. Thus, a complementary measure is needed to show such redistributions of financial burdens. The FI measure exclusively reflects the sustainability of a given

\footnotetext{
${ }^{16}$ Gokhale and Smetters (2003, p. 7).

${ }^{17}$ Gokhale and Smetters (2003, p. 8).
} 
policy, but another measure is needed to indicate how FI is distributed across population subgroups. Another measure is needed to indicate how much of the FI arises from older generations shifting tax burdens to younger (including yet unborn) generations. Gokhale and Smetters ${ }^{18}$ define this as the "generational imbalance" (GI):

$$
G I_{t}=P V E_{t}^{L}-P V R_{t}^{L}-A_{t} .
$$

$P V E_{t}^{L}$ represents the present value of projected outlays that will be paid to current generations, $P V R_{t}^{L}$ represents the present value of projected tax revenues from the same generations, and $A_{t}$ represents the NHS's current assets. Therefore, GI captures that part of FI arising from all transactions with past and living generations throughout their lifetimes. The projected contribution to FI by future generations equals the difference between FI and GI.

While the FI measure captures many large unfunded payment obligations not included in traditional accounting perspectives on the NHS, the GI measure captures the redistributive effect of alternative policies. Under the PAYG-financed NHS policy, the GI measure increases even though FI does not change. This implies that the imbalance on account of future generations decreases. It also suggests that policymakers must achieve two objectives simultaneously: first, reduce the FI to zero and second, choose a policy that delivers the best trade-off in costs imposed on different generations.

\section{Advantages of FI and GI}

Together the GI and FI measures provide a comprehensive accounting of the total future unfunded obligations of the NHS, which is implicit in the incidence of costs and the distribution of those costs across the various age groups contributing to and benefiting from NHS services. Identifying the GI component of FI is feasible for the NHS as outlays can be easily attributed to different individuals. This contrasts with other forms of U.K. Government expenditure as the benefits of outlays cannot easily be allocated to different generations or cohorts.

\section{Estimating GI and FI}

Gokhale and Smetters ${ }^{19}$ argue that both GI and FI possess a number of desirable characteristics. The first is that they are forward looking. Specifically, the large future obligations associated with the NHS are not reported in standard financial reports issued by either the U.K. Department of Health, by the U.K. Government under whole-ofgovernment accounting or by the NHS trusts themselves. Adopting a new forwardlooking performance measure would reveal a very different and more accurate picture of the NHS's financial status, as well as the size and nature of the needed policy adjustments.

A second desirable feature of a proper measure is that it should include all future years, that is, calculated in perpetuity. By contrast, annuity-based estimates do not completely account for the financial imbalances because of the arbitrary truncation of

\footnotetext{
${ }^{18}$ Gokhale and Smetters (2003, p. 11).

${ }^{19}$ Gokhale and Smetters (2003).
} 
the projection horizon. If deficits beyond the forecast horizon are large and growing, then annuity-based estimates will severely understate the full magnitude of the financial sustainability of such programmes.

Gokhale and Smetters ${ }^{20}$ argue that a third desirable feature of a financial measure is that it is complete, that is, it should encompass the operations of the NHS.

A fourth desirable property is that that the measure should be based on current policy. For a proposed measure to be useful, it must characterise current policy. By contrast, accrual accounting adopts a "shutdown" liability measure because it effectively assumes that the NHS will not be in existence in future years and therefore does not include future expected expenditures.

A fifth criterion argued by Gokhale and Smetters ${ }^{21}$ is that the measure should correctly reflect the impact of all policy changes. This includes the fact that the measure should not change when policy changes are actuarially neutral for all generations. It must also accurately reflect all actuarially non-neutral policies.

Finally, the sixth desirable feature argued by Gokhale and Smetters $(2003, \text { p. } 20)^{22}$ is that the measure should be conceptually straightforward and possess properties that are easy to communicate. The FI measure grows over time at the rate of interest. Hence, a change in the measure from one year to the next can be broken down into the amounts due to accumulated interest, policy changes, differences in economic outcomes relative to projections and updates to economic assumptions used in making budget projections. The GI measure is also simple because it equals the amount of FI due to current and past generations. However, other complementary measures could also be used, including ones that describe imbalances by narrowly defined birth cohorts, gender, rates and so on. We will analyse these various measures in the next section.

\section{Under-funding in the U.K. public health care sector}

The dominant factors in the health insurance market in the U.K. are as follows: (1) the existence of a compulsory universal health insurance scheme known as the NHS, operated by the U.K. Government; (2) as of 1998, a series of U.K. Health Care Agreements between the U.K. Government and each of the U.K. States and Territories to finance infrastructure expenditure in the public hospital system; and (3) the strict regulation of the private health insurance industry under legislation. This section provides an overview of the demographic trends affecting the demand for public health insurance in the U.K., followed by a brief overview of the historical trends affecting the financial management of the NHS. ${ }^{23}$

${ }^{20}$ Ibid. (p. 19).

${ }^{21}$ Ibid.

22 Ibid. (p. 20).

${ }^{23}$ This section draws from the relevant statistics provided by OHE (2006). It should be noted, however, that public health care does not cover private treatment in hospital, nor does it cover "gap" payments to doctors, or the services of dentists, physiotherapists, and other health professionals. Nor does it cover private pharmaceutical costs. The extent of these gaps also differs by region or local NHS trusts, leading to a "postcode lottery". It is these gaps that provide the opportunity for private insurance although, under present law, gap insurance for doctors' services is proscribed except in hospitals. 
The Geneva Papers on Risk and Insurance - Issues and Practice 750

Table 1 Incidence of recent health expenditure across the U.K.

Panel A: Across various countries of the U.K. (1975 is base year $=100)$

\begin{tabular}{lccccc}
\hline Year & England & Wales & Scotland & Northern Ireland & Total U.K. \\
\hline 1998 & 183 & 173 & 176 & 180 & 172 \\
1999 & 197 & 176 & 195 & 191 & 185 \\
2000 & 214 & 176 & 207 & 202 & 198 \\
2001 & 234 & 195 & 217 & 213 & 214 \\
2002 & 260 & 207 & 239 & 229 & 234 \\
2003 & 265 & 217 & 245 & 246 & 253 \\
\hline
\end{tabular}

Panel B: By type of expenditure (index 1975=100)

Year Hospital Community Pharmacy General medical General dental General ophtha Other services

\begin{tabular}{llllllll}
\hline 1998 & 151 & 308 & 289 & 225 & 163 & 82 & 252 \\
1999 & 157 & 325 & 308 & 235 & 163 & 91 & 282 \\
2000 & 170 & 348 & 322 & 245 & 169 & 94 & 312 \\
2001 & 178 & 327 & 335 & 245 & 172 & 95 & 407 \\
2002 & 188 & 388 & 363 & 258 & 174 & 93 & 450 \\
\hline
\end{tabular}

Panel C: NHS income by source

\begin{tabular}{lcccc}
\hline Year & Taxation & NHS contribution & Patient & Total expenditure \\
\hline 1998 & 39,064 & 5,691 & 939 & 48,138 \\
1999 & 41,037 & 6,162 & 1,006 & 52,264 \\
2000 & 44,569 & 6,690 & 1,058 & 57,067 \\
2001 & 49,103 & 6,905 & 1,168 & 62,892 \\
2002 & 54,114 & 7,610 & 1,296 & 70,196 \\
2003 & 60,406 & 8,494 & 1,531 & 78,015 \\
\hline
\end{tabular}

This table shows comparative estimates of the incidence of health expenditures, in the NHS for the last few years. Data obtained from OHE (2006), various tables.

Current trends in health care expenditure in the U.K.

Table 1 reports the main determinants of the incidence of costs in the NHS for the recent period 1998-2005. These are broken down by devolved U.K. country (panel A), type of expenditure (panel B) and source of income (panel C). Figures 1 to 4 also illustrate the major trends as identified in the Office of Health Economics (OHE). ${ }^{24}$ We briefly discuss the main features of these trends below.

The main points are that there is a significant set of expenditures in the NHS. The NHS costs allot more than those in other countries. The NHS pay rates and prices have grown over 800 per cent since 1975, which is significantly faster than the rate of inflation.

${ }^{24}$ Office of Health Economics (2006). 


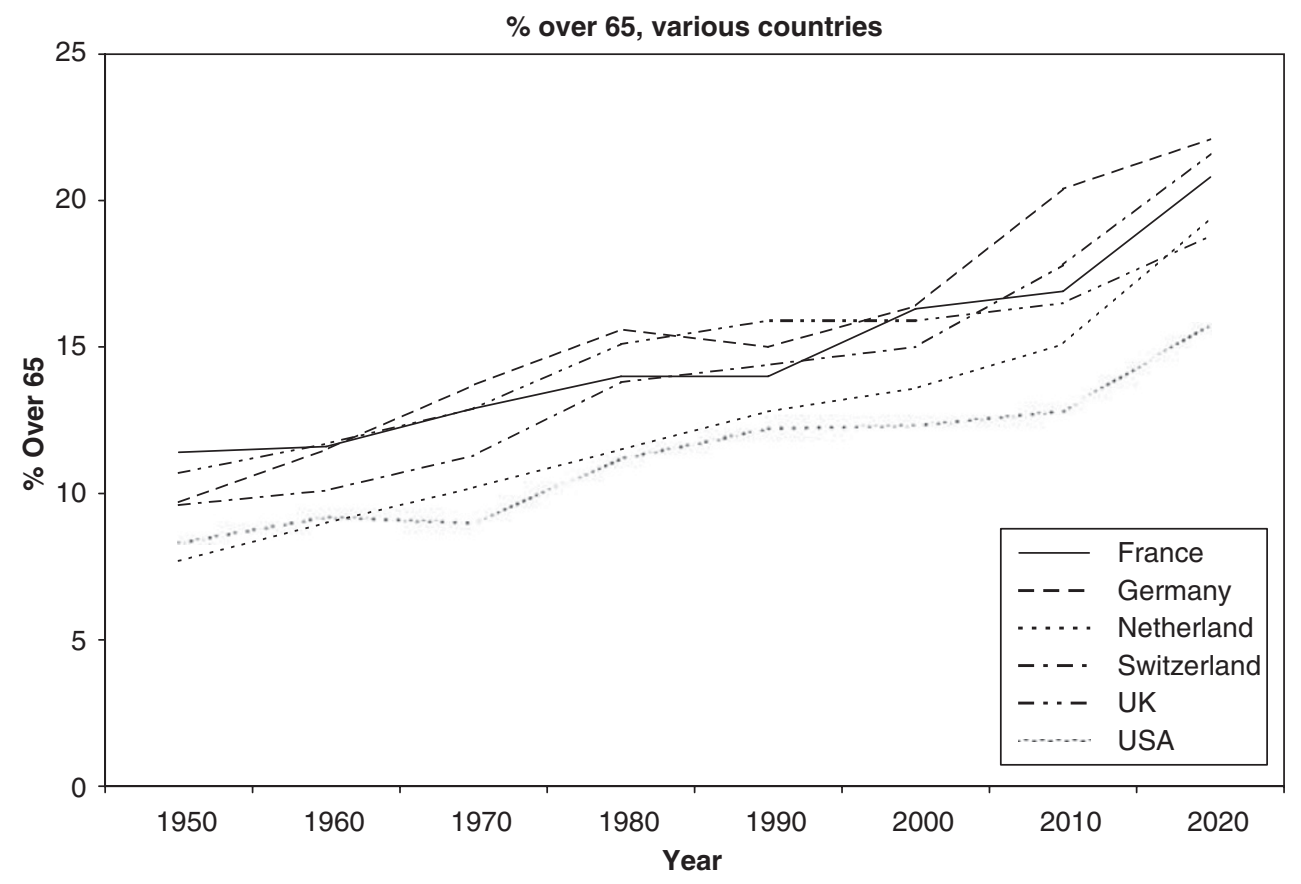

Figure 1. Percentage of total population over 65, various countries.

While average OECD health care expenditure as a fraction of GDP more than doubled between 1960 and 2003, the improvement in major health indicators over the same period has also been great. Infant mortality in OECD countries in 2003 was only 17 per cent of the 1960 level and male life expectancy at birth had increased to 75 years of age, compared with 66 years of age in 1960. The levels achieved in the U.K. in these key health indicators are similar to those in other rich countries.

The NHS was established on 5 July 1948, with the aim of providing a comprehensive range of health services to all U.K. citizens, financed by general taxation. The responsibility for the provision and development of health services lies ultimately with the Secretary of State for Health in England. The devolution of the U.K. created a separate competence over matters relating to health in Scotland, Wales and Northern Ireland.

After allowing for inflation, the NHS in 2004 cost eight-and-a-half times as much as in 1949 and the average cost per person has risen to just over seven times the 1949 level. The rate of rise in NHS expenditure over the past 5 years was also significantly faster than in the 5 years between 1994 and 1999. Outlay on the NHS has risen from 3.5 per cent of GDP in 1949 to 7.7 per cent of GDP in 2004. There has been a rapid rise in NHS spending relative to GDP.

According to OECD figures, the share of GDP devoted to public health expenditure (i.e. excluding patients' payments) in the U.K. is around the EU average and is above the OECD average at 7.1 per cent of GDP in 2003. This reverses the trend seen in the 1970s, 1980s, and 1990s when the U.K. devoted a smaller share of its GDP to public health care than most other OECD and EU countries. In 2003, public health 


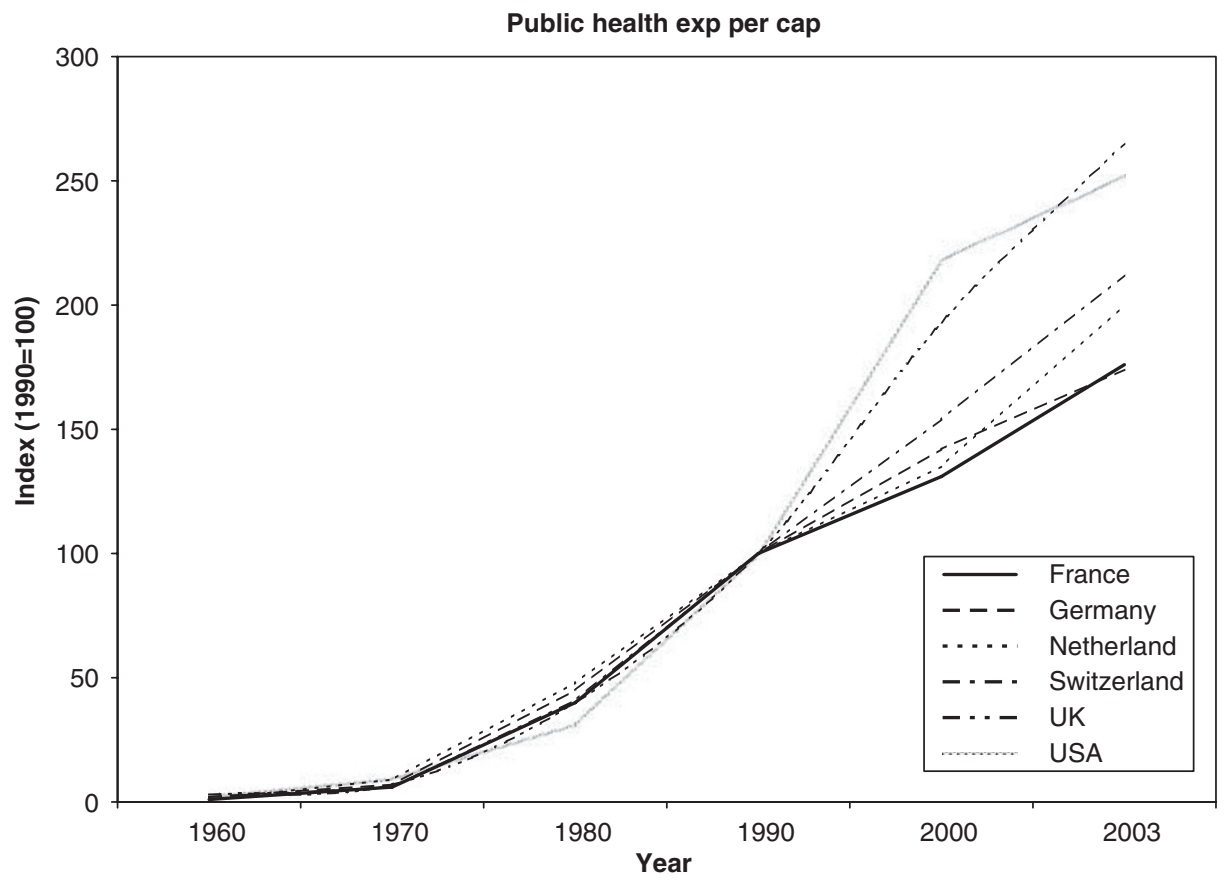

Figure 2. Public health expenditure per capita, various countries.

care expenditure per capita in the U.K. was 10 per cent above the EU 15 average and 28 per cent above the EU 25 average.

The rise in NHS costs is due to a variety of factors, such as pay and price inflation in the NHS, population growth and the expansion of services. There is a significant variation in expenditure per person by cohort. During 2002/2003, the NHS Hospital and Community Health Services (HCHS) in England spent an average of $£ 2,387$ for every person aged between 75 and 84 , and $£ 4,147$ for every person aged 85 years and over. These spending levels are several times greater than the average outlay on a person of working age (16-64 years). People aged 75 and over accounted for only 7.5 per cent of the population, but used 30 per cent of the HCHS budget during the financial year 2002/2003.

The pay bill is the single largest component of the NHS budget. Until 1990/1991, salaries and wages of directly employed personnel accounted for 76 per cent of gross annual revenue expenditure in the HCHS in England. This proportion appeared to drop significantly to 63 per cent after the inclusion of capital charges within measured revenue expenditure from this year onwards. The salaries and wages comprised 59 per cent of total expenditures in 2003/2004.

The inclusion of capital charges is a reflection of the increased reliance on Private Finance Initiatives (PFI) in the capital expenditure programmes of the NHS hospitals. However, the privatisation of these services has been controversial and has also led to 


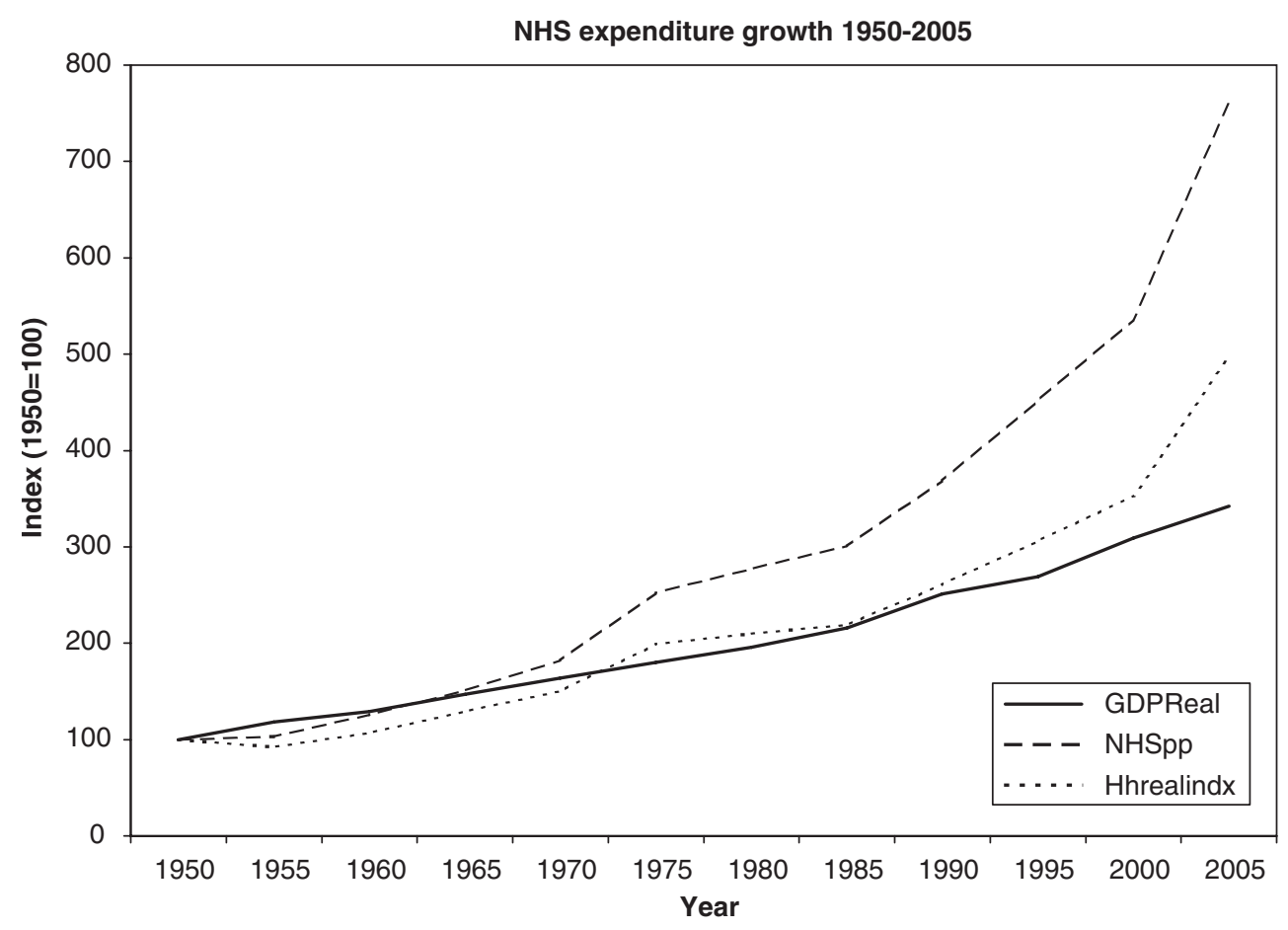

Figure 3. Growth in NHS public health expenditure, 1980-2005.

inconsistencies in accounting for these expenditures, depending on whether or not the PFI deal is structured in a way that permits on-balance-sheet or off-balance-sheet expenditures.

In real terms, the NHS pay bill has grown by roughly 100 per cent between 1985 and 2004. This can be partly attributed to the expansion of various sections of the workforce. Table 1, panel A, gives a breakdown of the total NHS expenditure by region (excluding centrally financed services). It shows that per capita health expenditure in England has been consistently lower than in the other four countries of the U.K. Relative to England, per capita spending on the NHS in 2003/2004 was 1 per cent higher.

The NHS reforms of 1991 also led to the adoption of new accounting methods, resulting in the difficulty of distinguishing between the costs of hospital services and community health services. Panel B of Table 1 shows the main categories of expenditure in recent years. The NHS budget now aggregates expenditure on hospital, community health and various minor services formerly classified under "other" services, plus the cash-limited expenditure of family health and related services.

Panel B of Table 1 gives the main breakdown of income sources. Of the total NHS expenditure in 2003, 78 per cent was financed directly by taxes. The NHS contributions paid by employers and employees via the National Insurance Scheme accounted for another 20 per cent. Contributions made by patients in the form of charges were historically a small and decreasing proportion of total NHS expenditures. They were only 2 per cent of NHS funding in 2003. 


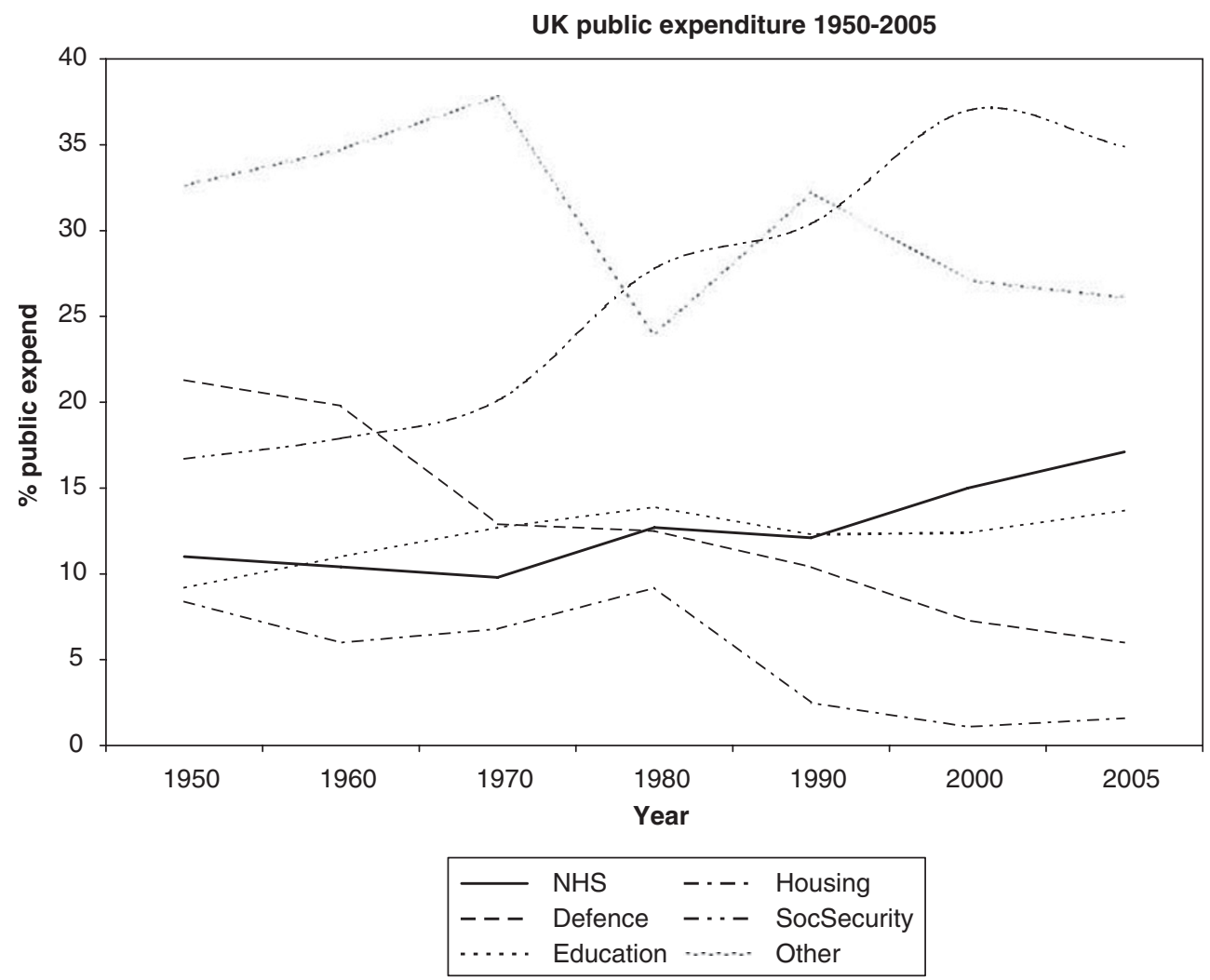

Figure 4. Public expenditure by category, 1950-2005.

The NHS accounted for 17 per cent of total U.K. public spending in 2002, its highest proportion ever and second only to Social Security at 34.9 per cent. NHS expenditure has varied from 9 to 18 per cent of total public expenditure. The increase in NHS costs has accelerated since 1999.

According to the latest government 2008 Comprehensive Spending Review, over the 3 years from 2008 to 2011, spending on the NHS is expected to rise from the 20042005 level of 6.9 per cent of GDP to 7.8 per cent of GDP.

\section{Demographic trends}

The starting point in looking at health care in the U.K. is the demography of the community. Two features dominate demographic trends. The first is the impact of two baby booms, which are still working their way through the U.K. population. One was born in the decade after the First World War and the other was born from the end of the Second World War through to the 1960s. There is a trough in the growth rate of the population arising from the relatively low birth rates between these two baby 
Table 2 Historical growth of the U.K. population and NHS services

\begin{tabular}{|c|c|c|c|c|}
\hline \multirow[t]{2}{*}{ Age group } & \multicolumn{2}{|c|}{ Per cent of total U.K. population } & \multicolumn{2}{|c|}{ Per cent using NHS outpatient services per person } \\
\hline & 1954 & 2004 & 1982 & 2003 \\
\hline \multicolumn{5}{|l|}{ Males } \\
\hline $0-4$ & 8.06 & 5.93 & 12 & 14 \\
\hline $5-14$ & 8.83 & 6.31 & 11 & 10 \\
\hline $16-44$ & 7.16 & 6.78 & 11 & 11 \\
\hline $45-64$ & 6.81 & 6.89 & 13 & 16 \\
\hline $65-74$ & 6.85 & 6.55 & 16 & 21 \\
\hline $75+$ & 15.14 & 13.51 & 18 & 24 \\
\hline \multicolumn{5}{|l|}{ Females } \\
\hline $0-4$ & 7.20 & 5.41 & 10 & 11 \\
\hline $5-15$ & & 5.76 & 8 & 9 \\
\hline $16-44$ & 11 & 6.17 & 11 & 13 \\
\hline $45-64$ & 13 & 6.23 & 13 & 18 \\
\hline $65-74$ & 6.29 & 6.16 & 15 & 20 \\
\hline $75+$ & 14.24 & 13.03 & 16 & 22 \\
\hline
\end{tabular}

This table shows comparative estimates of the gender and age distribution of both the U.K. population and NHS service rates in 1982, the first year when NHS was fully implemented, and in 2003. Data obtained from Table 3.40, OHE (2006).

booms and the people born then are now moving through the 60-70-year-old age group. This does not augur well for retirement villages and long-term care insurance in the immediate future.

The second significant factor in current U.K. demography is the decline in birth rates since the 1960s. In the last 30 years, birth rates have fallen by half among women in their early 20 s and by a quarter among women in their late 20s. It is among women of these ages that most births occur. There has been a minor increase in birth rates for women in their late 30s; however, the effects of this have been quite slight. Although the population has been growing slowly in recent years, the fertility rate has been below the replacement level since the 1970s. Consequently, the population has begun to age. This has important implications for the incidence of costs of the NHS beyond those of the basic breakdown above into regional and income and expenditure categories.

The OHE compendium also produces annual statistics showing the relative use of NHS-funded services by various cohorts of the U.K. population. These are shown in Table 2. Two trends are apparent from comparing the usage rates. First, it is apparent that the older-age cohorts use NHS-funded services significantly more than younger generations. Second, all cohorts are making increased claims on NHS-funded services now than 15 years ago. Moreover, most of this increase occurs for older-age cohorts, particularly for those aged 65-74 (a 95 per cent increase for men, a 47 per cent increase for women). When combined with the relative growth of the size of these cohorts over the period, the NHS translates into an ever-increasing burden on overall government sector finances.

The size and structure of the U.K. population is expected to experience substantial changes. Age and gender profiles for each generation are obtained from the U.K. 
Table 3 Projected size and age-gender distribution of the U.K. population

\begin{tabular}{|c|c|c|c|c|}
\hline \multirow[t]{2}{*}{ Age } & \multicolumn{4}{|c|}{ Year } \\
\hline & 2006 & 2026 & 2046 & 2066 \\
\hline \multicolumn{5}{|c|}{ Panel A: Fraction of males in specified age groups } \\
\hline $0-19$ & 0.255 & 0.239 & 0.223 & 0.218 \\
\hline $20-39$ & 0.279 & 0.264 & 0.257 & 0.244 \\
\hline $40-59$ & 0.273 & 0.245 & 0.244 & 0.243 \\
\hline $60-74$ & 0.133 & 0.155 & 0.146 & 0.151 \\
\hline $75+$ & 0.060 & 0.097 & 0.130 & 0.144 \\
\hline \multicolumn{5}{|c|}{ Panel B: Fraction of females in specified age groups } \\
\hline $0-19$ & 0.232 & 0.224 & 0.210 & 0.207 \\
\hline $20-39$ & 0.267 & 0.248 & 0.244 & 0.234 \\
\hline $40-59$ & 0.269 & 0.245 & 0.235 & 0.237 \\
\hline $60-74$ & 0.139 & 0.164 & 0.153 & 0.153 \\
\hline $75+$ & 0.093 & 0.119 & 0.158 & 0.169 \\
\hline
\end{tabular}

This table represents the average U.K. fertility (U.K. Government Actuarial Department, 2008). The data show that the age dependency ratio is expected to increase, while the working age population, which bears the costs of funding NHS, is expected to decrease.

Government Actuarial Department. ${ }^{25}$ Table 3 reports the age and gender profiles for the U.K. population changes based on replacement rate fertility. Twenty-year projections are made from 1990 to 2050.

These assumptions imply a rapid ageing of the U.K. population. Currently, 17 per cent of U.K. males and 23 per cent of females are aged 60 or older. By 2010, 20 and 26 per cent respectively of U.K. males and females will be in this age group under constant fertility assumptions. By the year 2030, over 23 per cent of the U.K. male and 29 per cent of the female population will be 60 and older if the fertility rate remains constant.

Table 3 suggests that the ongoing decline in the birth rates will affect the numbers of future taxpayers in U.K., the very ones who will be required to support social services to the ageing baby boomers. Clearly, given the mix of welfare and public health care systems, something has to give. However, demographic factors are not unique to the U.K., and although health care in the U.K. is a very big industry, spending on health care, as a percentage of gross domestic product (8.4 per cent of national GDP according to latest statistics), is fairly small relative to most other European and American countries and is only larger than Australia and New Zealand.

\section{Historical overview of the NHS}

The NHS was enacted in its present form by the U.K. Government in 1946, and commenced operations in the following year. It replaced an earlier, much amended

\footnotetext{
${ }^{25}$ U.K. Government Actuarial Department (2007).
} 
government health coverage scheme, which dated from 1911. The NHS is financed totally from general taxation. The NHS provides basic coverage for hospitals, for services provided by private medical practitioners and provides treatment without charge in public hospitals. There is a prescription charge for those not on benefits. Persons relying solely on NHS coverage in public hospitals do not have the right to choose the practitioners who treat them in hospital. They retain this choice outside hospitals.

Outside hospitals, doctors treating patients do so generally on a fee-for-service basis and may set their own fees and bill their patients directly. Patients may claim refunds from the NHS for the services received and must bear any difference from their own resources. Alternatively, doctors may bill the NHS directly for services rendered to patients ("bulk billing") in which case they are entitled to NHS payments only and are prohibited from charging patients any additional fees. Private "gap" insurance is prohibited for services outside hospitals.

During the past 60 years, the U.K. health care system has been dominated by the waxing and waning of the NHS, under which free public hospital services are available to all, without means testing and free doctor services are available. Under its current guise, the NHS does not cover private treatment in hospital. It also does not cover private pharmaceutical costs. Nevertheless, a major feature of the NHS experience has been the rapid rate of growth in its costs. ${ }^{26}$

\section{Analysing the under-funding of the NHS}

This section analyses the under-funding of the NHS in terms of standard accounting principles now applied in the U.K. public sector. First, the extent of annual underfunding in the NHS is identified. Limitations of both cash- and accrual-based accounting principles in defining the size and nature of this under-funding are then discussed.

\section{Past under-funding of the NHS}

Under-funding of PAYG public health insurance systems around the world is relatively common and arises in one of two ways. One method of under-funding, for programmes with specifically allocated government trust funds (e.g. the United States), is to adopt unrealistic assumptions that reduce legally required contributions by government. For example, the spread between the assumed rate of return on investments of accumulated contributions and the rate of assumed benefit claim growth determines, in effect, the real discount rate applied to health care liabilities. The larger the spread between these two, the lower the present value of calculated obligations. The other form of under-funding, for programmes where no specific trust

\footnotetext{
${ }^{26}$ The adoption of accrual accounting in the recording of these expenditures means that the vast proportion of these expenditures is recorded as "recurrent": capital expenditure and consumption appear to be immaterial. However, this analysis omits the future obligations likely to be imposed on future taxpayers from privately financed capital expenditure projects required to maintain public infrastructure, which Mayston (1999) suggests may be quite substantial in the U.K. However, because most public hospital infrastructure is managed by the individual States rather than the Commonwealth, it is not possible to establish the impact of capital expenditure requirements on the funding status of the NHS.
} 
Table 4 U.K. government funding of the NHS - 2001/2002-2005/2006

\begin{tabular}{|c|c|c|c|c|c|}
\hline & $\begin{array}{l}2001 / 2002 \\
\quad(£ m)\end{array}$ & $\begin{array}{l}2002 / 2003 \\
\quad(£ m)\end{array}$ & $\begin{array}{c}2003 / 2004 \\
(£ m)\end{array}$ & $\begin{array}{l}2004 / 2005 \\
(£ m)\end{array}$ & $\begin{array}{c}2005 / 2006 \\
(£ m)\end{array}$ \\
\hline National Health Service & 51,994 & 55,405 & 61,886 & 66,873 & 74,168 \\
\hline \multicolumn{6}{|l|}{ Of which: } \\
\hline Hospital services & 49,082 & 52,448 & 58,412 & 63,373 & 70,757 \\
\hline Family health services & 1,951 & 2,024 & 2,141 & 2,129 & 2,131 \\
\hline Central health services & 649 & 600 & 993 & 1,062 & 979 \\
\hline Department administration & 312 & 333 & 320 & 309 & 300 \\
\hline Personal social services & 729 & 1,590 & 1,617 & 2,110 & 2,070 \\
\hline NHS superannuation & 3,949 & 4,569 & 6,194 & 6,396 & 9,281 \\
\hline Other & 76 & 96 & 100 & 54 & 128 \\
\hline Total expenditure & 56,749 & 61,660 & 69,776 & 75,434 & 85,647 \\
\hline
\end{tabular}

This table summarises the most recent data concerning the U.K. Government's funding of the NHS programme, based on the government's own budgetary records for each year 1995-1998. Data are obtained from the U.K. Department of Health, Annual Report (2007), Department of Health Public Spending (Core Table No. 1, 190). It should be noted that the annual calculated deficit figure is a nominal figure only, since NHS receipts and expenditures are not separated out from those related to other types of health care programmes and are not therefore accumulated over time. Consequently, this figure is not recognised in the U.K. Government's Whole of Government Accounts.

funds are set aside (e.g. the U.K., New Zealand), involves the failure of the government to actually contribute enough on a year-by-year basis to meet its calculated obligation to fund benefit payments.

The U.K. Government's annual funding of health services takes a number of different forms. It includes direct benefit payments and subsidies to individuals, payments to non-government service providers and provider organisations, purchases of goods and services, and specific purpose payments to state and local governments to support health services provided by or through them. The NHS-related expenditures have in the past been made annually in the budget and accounted for on a cash accounting basis; these are broken down into three categories: medical benefits, pharmaceutical benefits and government grants. ${ }^{27}$

Table 4 summarises the effect of both growing expenditures on the NHS from the perspective of the U.K. Government's Department of Health. ${ }^{28}$ It should be noted that, unlike the aggregate estimates reported in Table 1, these values are based on figures contained in the Annual Budgetary Statements produced by the government. Until now, these have been based on cash accounting principles and thus there is no matching between services provided to different generations and taxation revenues

\footnotetext{
${ }^{27}$ These expenditures are made through Health Care Agreements under which the government provides funding for NHS public hospitals and related health services usually involve considerable political disputes. Recently, a number of these have been privately financed via the Public Finance Initiative.

${ }^{28}$ Department of Health (2007).
} 
derived from them, and no recognition that the health care system is acquiring future liabilities that may not be matched by the available assets.

Table 4 shows that the NHS produces an annual net deficit of around $£ 60$ billion per year for the U.K. Government. There are three important accountability implications of this analysis. First, these figures are not currently publicly reported in the U.K. Government accounts, as under current accounting rules, the NHS is aggregated with other Health and Age Care-related expenditures and taxation revenues. ${ }^{29}$ Second, taxes collected under the national insurance contribution are annually incorporated into the U.K. Government's Consolidated Revenue Account. Thus, the accumulation of these deficits is not recognised under cash-based accounting principles previously used by the U.K. Government. Third, these figures do not include health care expenditures incurred by individual U.K. local governments on health care expenditures, which in aggregate totalled 23.6 per cent of total U.K. health services expenditures in $1998 .^{30}$

\section{Re-defining the NHS deficit under accrual-based accounting principles}

The above analysis of the under-funding of the NHS was based on a crude identification of annual net cash flows associated with this programme. By contrast, under current full accrual-based accounting principles, a surplus or deficit for any accounting entity should be much broader than this, as it should represent the difference between the "true costs of services being provided and the actual revenue collected from the community to meet those costs". 31 The U.K. Government's public accountability for the size and nature of its obligations under the NHS are likely to be affected by the development of new professional U.K. Accounting standards that have recently been specifically promulgated for application to the U.K. public sector. The U.K. Exposure Draft Financial Interpretation for Public Benefit Entities of the Statement of Principles for Financial Reporting (hereinafter FIPBE) was prepared by the U.K. Accounting Standards Board in June 2006. The proposed standard applies to financial reports prepared by all U.K. government entities in 2008.

According to FIPBE, the general purpose of financial reports prepared by government entities is to provide information about inter-generational equity, which is concerned with the appropriate balance between taxation and borrowings to finance current period services and capital infrastructure. Information about intergenerational equity is claimed to help users assess whether future generations are required to assume the burden of financing current period services and to assess whether current and future generations equitably contribute to the stock of infrastructure.

FIPBE requires adoption of the full accrual basis of accounting. Accrual accounting is where assets, liabilities, equity, revenues and expenses are recognised in the reporting

\footnotetext{
${ }^{29}$ There are currently no requirements in the U.K. public sector (even with the adoption of accrual-based accounting principles) for the production of financial statements for individual government programmes, including those related to the provision of social insurance.

${ }^{30}$ U.K. Institute of Health and Welfare (1999).

${ }^{31}$ Mackintosh (1992).
} 
periods to which they relate, regardless of when cash is received or paid. This means that assets, liabilities, revenues and expenses arising from transactions or other events must be recognised in the financial statements when they have an economic impact on the government entity, regardless of when the associated cash flows occur. This standard requires governments to prepare accrual-based general purpose financial reports which include the assets they control, the liabilities they have incurred, and their revenues and expenses so that their financial reports provide users with a comprehensive summary of their financial performance and financing and investing activities.

However, accrual-based accounting principles provide limited insights into the financial dimensions of under-funded public health care systems such as the NHS for a number of reasons. First, they express the financial status of the NHS in terms of the periodic relationship of total "contributions" levied through taxation levy and total benefits as "expenses".

Second, accrual-based accounting principles are usually applied to many public or private sector entities where the timing of revenues and expenditures can be easily matched and are periodically funded accordingly. However, this is not the case for the NHS. Indeed, while government revenues are realised as soon as they are earned from the national insurance contribution, there is no readily identifiable equivalent expense as its occurrence is contingent upon a future probabilistic event (i.e. the incurrence of medical benefits). Indeed, the effects of demographic shifts on PAYG financing of the NHS means that there is unlikely to be any economic relationship between the government's revenue from the national insurance contribution (i.e. working-age earning individuals) and its expenditures required to meet benefit claims on the NHS (older-age retirees). ${ }^{32}$

Third, even if there was a nominal relationship, it is unlikely that the government's NHS benefit obligations would be recognised under accrual-based accounting principles. This is because, as defined in International Accounting Standards, a liability must be recognised in the statement of financial position when and only when: (a) it is probable that the future sacrifice of economic benefits will be required, and (b) the amount of the liability can be measured reliably. However, it is uncertain whether future commitments of the U.K. Government to meet future NHS benefit payments can be treated as liabilities under this definition.

Finally, as HM's government is a going concern that cannot "go out of business", accrual accounting does not capture a potential mismatch between future contributions to be paid by living generations and benefit accruals arising from them. GI captures those elements properly. They may be significant because a large or emerging and growing GI may trigger policy changes sooner rather than later and policies of a different kind compared to if this information were available earlier via reporting the GI. ${ }^{33}$

${ }^{32}$ Barton (1999) develops similar criticisms concerning the application of accrual-based accounting principles as defined by FIPBE to the Australian public sector.

${ }^{33}$ Under equivalent proposed accrual-accounting based Whole of Government reporting principles as set out by H.M. Treasury (1998), liabilities for national insurance and other social insurance programmes are not recognised because they represent moral rather than legal obligations of government (paragraph 90). However, whether similar considerations apply to all or parts of the U.K. Government's obligation to pay for benefits under the NHS Benefit Schedule remains unclear. Our thanks to Jagadeesh Gokhale for pointing this out. 


\section{Cost incidence of NHS under-funding patterns}

The traditional focus on publicly held debt, therefore, creates a bias in decision making against potential reforms to the NHS that could reduce the government's FI. This bias is especially problematic given the large existing imbalances. A more complete accounting, which explicitly recognises the future net obligations of Medicare, would reduce this bias.

This section reports estimates of total NHS FI and, where appropriate, the GI for the NHS under the assumption that the budget's policies represent "current policies". This so-called policy-inclusive treatment of the NHS budget is consistent with the approach taken by Gokhale and Smetters ${ }^{34}$ and with how the U.K. budget is presented. The calculations are based on long-term budget projections. The U.K. Government, in contrast to the U.S. Government, does not provide any long-term budget projections. We therefore take the U.K. long-term rate as being consistent with that of H.M. Treasury, ${ }^{35}$ projected to 2058, and therefore include their economic assumptions; these include a real GDP per capita growth rate of 1.7 per cent per year after 10 years, and we use a real discount rate of 3.6 per cent per year to correspond to the average yield on 30-year Treasury bonds over the last 10 years.

The most important assumption is the future growth rate in real health care outlays per capita. Consistent with H.M. Treasury's latest long-term public finance forecast, ${ }^{36}$ the baseline assumes that real health care outlays per capita will continue to grow at an annual rate, that is 1 per cent higher than the growth rate in U.K. GDP per capita until 2058. Between 2058 and 2100, this differential is consistent with the approach taken in Gokhale and Smetters, ${ }^{37}$ and constructing the GI measures for Medicare as well as extending H.M. Treasury's ${ }^{38}$ projections beyond 2058 required detailed work using micro-data sets. In particular, we follow Gokhale and Smetters ${ }^{39}$ and constructed eight age-gender profiles using various micro-data relating to each tax category.

These age-gender profiles were then used to decompose the H.M. Treasury's ${ }^{40}$ longterm estimate numbers by generation before 2058 and then to extend the H.M. Treasury's numbers beyond 2058 using demographic projections relevant for those years. The age-gender profiles also allow us to break down the revenue side of the rest of government finances by generation. The profiles must be indexed by age, as the amount and type of taxes paid vary by age. These profiles must also vary by gender because women are projected to live longer than men, and therefore pay different levels of taxes and receive different levels of benefits.

The majority of the NHS's FI arises from future generations (FI minus GI) rather than from past and current generations (GI). The reason for future generations'

\footnotetext{
${ }^{34}$ Gokhale and Smetters (2003).

${ }^{35}$ H.M. Treasury (2008).

36 Ibid.

${ }^{37}$ Gokhale and Smetters (2003).

${ }^{38}$ H.M. Treasury's (2008).

${ }^{39}$ Gokhale and Smetters (2003).

${ }^{40}$ H.M. Treasury (2008).
} 
significantly larger contribution is the rapid projected growth in NHS outlays per capita during the next several decades. These are assumed to gradually reduce to zero, so that health care outlays per capita grow as a share of GDP because of population ageing after 2100 . The assumptions are more conservative relative to historical experience. To the extent that real increments or reductions in a deficit indicate that future generations must help pay for the provision of NHS services to the current generation, a full accrual set of financial statements provides useful information to facilitate the financial management of social insurance programmes such as the NHS. However, for the reasons explained above, accrual accounting statements provide only part of the information required to assess issues of intergenerational equity. ${ }^{41}$

In this section, the concept of FI and GI is introduced as an alternative system for evaluating the effects of ongoing demographic change on the funding status of public health care systems such as the NHS.

These models are based on the annual estimates of lifetime contributions (in the form of national insurance contribution payments) of each age cohort to the U.K. Government, less the estimates of lifetime NHS benefits receivable by them, all suitably discounted to their present values. A zero net present value at birth of net contributions indicates that each cohort is just "paying its way" ${ }^{42}$ A negative (or positive) figure indicates that the cohort is effectively being subsidised (or taxed) by other generational cohorts in the form of "inter-generational transfers".

FI less GI makes these inter-generational transfer values explicit by calculating the discounted present value of demographically induced under-funding of PAYGfinanced NHS that is attributable to current and future generations of contributors and recipients. The calculations must be based on far-reaching assumptions of life expectancy, incomes, economic growth, tax rates, costs of providing services, inflation rates and discount rates. Thus, these models provide a basis for judging whether the continuation of current policies should enable each generation to fund the provision of NHS services to it or whether their provision depends on future generations contributing to them as well as their own benefits. ${ }^{43}$

These calculations are at odds with most currently accepted accounting measurement systems for government financial reporting such as current cost or current market value. However, accountants must often use estimated future cash flows as a basis for measuring assets and liabilities for a variety of purposes. ${ }^{44}$

${ }^{41}$ The Financial Accounting Standards Board (FASB) requires all U.S.-based employers to account for their health and long-term care benefits obligations to their employees (SFAS 106).

${ }^{42}$ Barton (1998).

43 Ibid.

${ }^{44}$ Discounted cash flow calculations are gaining increasing popularity in financial reporting practices of other industries subject to long-term cash flows (e.g. oil and gas, life insurance, and pensions). They have also motivated special studies on the subject of present value (Lovejoy et al., 1989; Upton, 1996) and in 1997 the Accounting Standards Board published a working paper on the subject (Accounting Standards Board, 1997). The FASB has now incorporated the objectives and conceptual basis for using present value techniques in financial accounting measurement in its conceptual framework. 
Table 5 Fiscal and generational imbalances for NHS net contributions by existing and future generations

\begin{tabular}{|c|c|c|c|}
\hline Generation of NHS participant & $r=0.02(£ m)$ & $r=0.04(£ m)$ & $r=0.06(£ m)$ \\
\hline \multicolumn{4}{|l|}{ (1) Male generations } \\
\hline $75+$ & -16 & -16 & -16 \\
\hline $60-74$ & 1,198 & 974 & 837 \\
\hline $40-59$ & 1.896 & 1,410 & 1,099 \\
\hline $20-39$ & 1,236 & 602 & 306 \\
\hline Subtotal & 4,267 & 2,970 & 2,227 \\
\hline \multicolumn{4}{|l|}{ (2) Female generations } \\
\hline $75+$ & -19 & -19 & -19 \\
\hline $60-74$ & 1,130 & 957 & 823 \\
\hline $40-59$ & $-1,831$ & 1,359 & 1,059 \\
\hline $20-39$ & 748 & 434 & 259 \\
\hline Subtotal & 7,957 & 5,702 & 2,122 \\
\hline (3) Future generations & $-8,021$ & $-5,766$ & $-4,349$ \\
\hline (4) Government wealth & 2 & 2 & 2 \\
\hline (5) PV government consumption & -65 & -65 & -65 \\
\hline
\end{tabular}

The projected study period is to 2058 (using H.M. Treasury, 2008 estimates) and in perpetuity thereafter assuming growth occurs at GDP plus 1 per cent. All amounts are expressed in constant 2005 millions of U.K. pounds. The generational accounts for each cohort represent the difference between contributions (in the form of national insurance contribution) and benefit payments received. A negative GI indicates that the generational cohort is receiving net benefits from the NHS. The net contribution for each generation was calculated by dividing the total aggregate contributions by the total number of participants (or beneficiaries), then multiplying by the fraction of total members in the relevant generational cohort (as per Table 4). These are then discounted to the present using three different interest rate scenarios, which have a significant bearing on the size of the GI. The interest rate $r$ represents, in real terms, the assumed net difference between the projected rate of interest on NHS contributions and the growth rate of NHS services (assumed to be equal to the current U.K. rate of inflation).

\section{Sources and data construction}

The construction of FI and GI involves three steps. The first step is to project the ageing of the population over a relevant time period (in this case, dating from the NHS's effective implementation in 1986). The second step entails projecting each currently living generation's average contributions less benefits in each future year during which at least some members of the generation will be alive. The third step converts these projected average contributions into a present value using an assumed discount rate and taking into account the probability that the generation's members will be alive in each of the future years (i.e. discount for both mortality and interest). It is initially assumed that the real return available to U.K. health care funds over this period is 2 per cent. This rate is based on the current risk free rate of interest available for U.K. Government bonds (approximately 5 per cent), net of inflation (approximately 3 per cent). However, to examine the sensitivity of the size of FI to this interest rate assumption, alternative calculations are based on more conservative rates of 4 and 6 per cent. To account for the rapidly increasing probability of death after average life expectancy has been reached, the discount rate used in the 
computation of benefits paid to the oldest cohort, which no longer contributes to the national insurance contribution (i.e. aged over 65), is held constant at 12 per cent.

It is assumed that the size and age-gender distribution of the population is based on the latest available data used by the U.K. Bureau of Statistics ${ }^{45}$ population projections (i.e. 2005). Inferring the funding burden on future generations requires knowing not only the total sum of generational accounts of current generations, but also the health system's initial financial position and the projected present value of its contributions. The initial financial position is estimated in a manner consistent with the fund's under-funded liability as reported in annual accounts. The estimates of the present value of net contributions by current generations are net of all other taxes.

In order to construct the generational accounts, the contributions listed in the annual accounts are decomposed into those by taxpayers and subsidies provided by government. The NHS claims are not available; equivalent data was taken from Australian Government reimbursements of expenditure for medical treatments and consultations. Income and expenditures are based on average rates in the period from 1998 to 2004 and are taken from the OHE. ${ }^{46}$ These are imputed to each generational cohort in proportion to their allocated holdings of gross benefit entitlements, as shown in Table 4.

Table 5 presents baseline FI and GI estimates, respectively, for three cohorts of male and female NHS participants, for three different combinations of wage growth and interest rates. The table assumes that in the year 2005, the U.K. fertility rate will stabilise the population. All amounts are in 2005 U.K. pounds. The accounts indicate the average amount an individual in the specified age-gender group will pay in contributions over the rest of his/her working life. Notice that all existing generations have negative generational accounts. They are expected to receive, in present value, more in future health care benefits than they are expected to contribute to the fund. The size of the GI first rises and then falls with age. This reflects the fact that young employees are years away from their peak contribution paying years, while older employees are in or near their retirement years in which they are on the receiving end of the NHS system.

In addition to detailing the remaining lifetime payments of current generations, Table 5 indicates in the last row the contributions required of future generations (i.e. FI less GI), assuming that they pay the same amount except for growth. ${ }^{47}$

The comparison of the first and next to last rows in Table 4 shows a very large sensitivity of the imbalance in the generational stance of health care funding to the interest rate assumption used. For the three combinations of interest rate assumptions, future taxpayers will be required to contribute, in present value, somewhere between 9 and 10 times the amount new employees are expected to contribute, given current funding policy. Under the base assumption of a 2 per cent real interest rate, future taxpayers will need to contribute about 10-fold what 2005 new taxpayers paid.

${ }^{45}$ U.K. Bureau of Statistics (2006).

${ }^{46}$ Office of Health Economics (2006).

${ }^{47}$ The calculation of the burden on future generations assumes that the ratio of the burden on future tax-paying males relative to that on future females is the same as the ratio of the accounts of current tax-paying males to females (i.e. that in the future males will be treated by the NHS relative to females in the same manner as new taxpayers are slated to be treated). 
As the table indicates, which values one assumes for the interest and growth rates has an important effect on the size of the GI. The extent of the GI is also quite sensitive to the growth and interest rate assumptions. The higher the interest rates, the larger the absolute value of FI. Higher interest rates increase the percentage difference in accounts of current and future new employees. Besides the sensitivity to assumptions on the interest rates, the results might also be affected by other specific assumptions, mainly concerning the effect of medical sciences and usage of public health services on evolution of NHS benefits, the assumed value of infrastructure assets related to the public health care system, and the uncertainty surrounding the demographic projections. ${ }^{48}$

\section{Conclusion}

This paper explores the accountability and financial management dimensions of the U.K.'s PAYG-financed universal public health service, the NHS. The financial sustainability of NHS finances is only partly PAYG financed via national insurance contribution taxes and in any case is sensitive to the ageing of the U.K. population. The apparently large annual cash shortfall of the U.K. Government's national insurance contribution revenues in relationship to NHS benefit payments in recent years is not publicly reported. Analysis of this shortfall indicates that very little effort is being taken to plug the under-funding gap created by the NHS. Since the effects of demographic change on the financial viability of NHS are uncertain and are only likely to become known in the longer term, it is argued that this lack of accountability will not be adequately addressed through existing forms of the implementation of accrual-based accounting principles.

Standard generational accounting estimates of GI imply strong assumptions about policy sustainability and in any case involve strong assumptions about the duration of the obligation. In this paper, an alternative set of financial and generational imbalance measures are estimated, based on the approach developed by Gokhale and Smetters. ${ }^{49}$ These measures provide an alternative perspective into the likely sources of underfunding in order to evaluate who pays, and when, for the under-funding of the NHS, given current policy assumptions. The analysis shows that the GIs of younger generations, and especially future generations, are positive while those of older generations are negative. This implies current and future generations are effectively financing the current, relatively intensive use of NHS-funded health services by older generations.

\footnotetext{
${ }^{48}$ There are currently no reliable means of valuing the current net asset worth of the NHS system's infrastructure assets. Although the U.K. Government accounts are currently under preparation which purport to show these, presently reliable figures are not available. To the extent that these assets can be assessed at "current" or market value, their inclusion in the generational accounts would significantly bear upon the magnitude of the generational accounts, although it would not impact the relative impact on generational cohorts.

${ }^{49}$ Gokhale and Smetters (2003).
} 
In constructing GI and FI measures, various assumptions are made about the relationship of growth, inflation, and demographic growth rates. It should also be noted that the measures only seek to represent the direct financial impact of the NHS on each generational cohort. However, they ignore indirect benefits conferred on middle-aged generations who no longer have to carry the primary burden for their parents. Further, the particular rate of discounting determines the entire pattern of burden and reward that the PAYG-financed NHS confers on individual generational cohorts. Thus, the interpretation of the results of the analysis for policymakers should be viewed with caution at this point.

Nevertheless, GI implies that a serious generational funding imbalance arises from the demographics of ageing populations as a result of the continuing reliance on PAYG financing of the NHS. Were there a relatively large and growing cohort of existing and future taxpayers to contribute moneys to these systems, the results of the analysis would be less troubling. But the population in the U.K., as in many other western economies is rapidly ageing. This implies that, while the demand for NHS services by older generations will continue to grow in both size and intensity, the sources of funds required to supply a given level of service (i.e. the NHS levies paid by younger working-age generations) will continue to decline.

The analysis also raises serious questions over the reliability of (short-term) performance measures that are now increasingly being used to evaluate the financial management of publicly financed health care services. This is because ageing populations imply that severe inter-generational inequities can be involved in PAYG financing of these services, that in turn may also underlie calculated cost and profit efficiencies that affect the long-term demand for, and supply of, these services. It is unlikely that these issues can be resolved by simply drawing up fixed short-term contracts that affect service delivery (e.g. agreements with third parties to provide recurrent services or private sector finance to fund major capital expenditures).

This paper has demonstrated that the concept of GI may have important policy implications for understanding the accountability and financial management of under-funded, PAYG-financed public health care systems. It is expected that future research will examine the implications of FI and GI in other inter-generational equity sensitive public policy settings, such as environment and pensions.

\section{References}

Ablett, J. (1996) 'Intergenerational accounting and saving in U.K.', The Economic Record 72: 236-245.

Accounting Standards Board (1997) Discounting in Financial Reporting, London: ASB.

Appleby, J. (1992) Financing Health Care in the 1990s, London: Open University Press.

Auerbach, A.J., Gokhale, J. and Kotlikoff, L.J. (1991) 'Generational accounts: A meaningful alternative to deficit accounting', in D. Bradford (ed) Tax Policy and the Economy, Cambridge, MA: MIT Press.

Barton, A. (1998) The usefulness of accrual accounting for government resource management, working paper, Canberra, Australia.

Barton, A. (1999) 'Public and private sector accounting - The non-identical twins', U.K. Accounting Review 9: $22-31$.

Chua, W.F. and Preston, A. (1994) 'Worrying about accounting in health care', Accounting, Auditing and Accountability Journal 7(3): 4-17. 
Danzon, P. (1993) 'Can our social insurance systems survive the demographic shifts of the twenty-first century?', in A.M. Rappaport and S.J. Schieber (eds) Demography and Retirement: The Twenty-First Century, New York: Praeger.

Department of Health (2007) Departmental Annual Report 2007, London: The Health and Personal Services Programmes, Stationary Office.

Gokhale, J. and Smetters, K. (2003) Fiscal and Generational Imbalances: New Budget Measures for New Budget Priorities, Washington, DC: American Enterprise Institute.

Hagist, C. and Kotlikoff, L.J. (2005) Who's going broke? Comparing healthcare costs in 10 OECD countries, NBER working paper 11833, Washington, DC.

H.M. Treasury (1998) Whole of Government Financial Reporting, London: HMSO.

H.M. Treasury (2008) Long-Term Public Finance Report: An Analysis of Fiscal Sustainability, London: HMSO.

Klumpes, P.J.M. (2001) 'The financial accountability of Australia's medicare system: A generational accounting analysis', Financial Accountability and Management 17: 171-190.

Lapsley, I. (1998) 'Constructing health care accountants: Melding calculation and care', Management Accounting Research 8: 31-35.

Lawrence, S., Alam, M. and Lowe, T. (1994) 'The great experiment: Financial management reform in the NZ health sector', Accounting, Auditing and Accountability Journal 7(3): 68-96.

Loeb, S.E. (1987) 'Population aging: Some accounting considerations', Journal of Accounting and Public Policy 6: 1-14.

Lovejoy, C., Peasnell, K., Taylor, P. and Talukdar, S. (1989) Discounting in Corporate Financial Reporting, London: Institute of Chartered Accountants in England and Wales.

Mackintosh, I. (1992) Accrual Accounting for Departments and the Whole of Government: Costs, Benefits and Opportunities, Melbourne: Australian Society of CPAs.

Mayston, D. (1999) 'The Private Finance Initiative in the National Health Service: An unhealthy development in new public management?', Financial Accountability and Management 15: 249-274.

OECD (2006) Projecting OECD Health and Long-Term Care Expenditures: What are the Main Drivers? Paris: OECD.

Office of Health Economics (OHE) (2006) Compendium of Health Statistics 2005-2006, London: OHE.

U.K. Bureau of Statistics (2006) Annual Statistics, London: HMSO.

U.K. Department of Health (2007) Annual Report, London: The Stationary Office.

U.K. Government Actuarial Department (2007) U.K. Population Demographics, London: HMSO.

U.K. Government Actuarial Department (2008) U.K. Population Trends, London: HMSO.

Upton, W.S. (1996) The FASB Project on Present Value Based Measurements, an Analysis of Deliberations and Techniques, Norwalk: FASB.

\section{About the Authors}

Paul J.M. Klumpes is a professor of Accounting at the Tanaka Business School of Imperial College, London. Paul holds bachelor degrees in Commerce and Law, a master's degree in Commerce, and a $\mathrm{PhD}$ degree in Accounting. He is also an Australian CPA and an honorary fellow of the Institute of Actuaries. His research interests cover the inter-relationship of public policy and voluntary reporting, regulation, financial management, and control of financial services, particularly related to pensions and life insurance.

Liyan Tang is a research fellow at the Tanaka Business School of Imperial College, London. Liyan is a PhD candidate in Accounting. She holds a bachelor degree in Economics and a master's degree in Finance. 